\title{
Mineração
}

\section{Distribuição de tempos de residência da polpa em células mecânicas de flotação}

Odair Alves de Lima

Doutorando em Engenharia Mineral-EPUSP

Departamento de Engenharia de Minas e de Petróleo, Escola Politécnica Universidade de São Paulo, São Paulo, SP, Brasil.E-mail: odair.lima@poli.usp.br

Laurindo de Salles Leal Filho

Prof. Titular da Escola Politécnica da USP Departamento de Engenharia de Minas e de Petróleo, Escola Politécnica Universidade de São Paulo, São Paulo, SP, Brasil. E-mail: lauleal@usp.br

Anatália L. Silva Engenheira da Rio Paracatu Mineração - RPM, Paracatu, Minas Gerais, MG, Brasil

Armando J. Moura Engenheiro da Rio Paracatu Mineração - RPM, Paracatu, Minas Gerais, MG, Brasil

\section{Resumo}

A técnica denominada Distribuição dos Tempos de Residência (DTR) constitui em um instrumento largamente utilizado pela indústria mineral, para estimar a qualidade da mistura que ocorre dentro das células de flotação. A técnica consiste em adicionar um traçador na entrada das células, controlando sua concentração na saída. Os resultados da aplicação dessa técnica são: a função DTR, o tempo médio de residência $\left(t_{m}\right)$ e a variância $\left(\sigma^{2}\right)$. Esse trabalho apresenta e discute a aplicação da técnica DTR nas células mecânicas de flotação da Rio Paracatu Mineração, localizada em Paracatu-MG. Os resultados indicaram quais células operavam em melhores ou piores condições de mistura.

Palavras-chave: Flotação, hidrodinâmica, distribuição dos tempos de residência (DTR).

\section{Abstract}

The Residence-Time Distribution (RTD) technique is a tool widely used in the mineral industry for assessing the mixture quality found in flotation cells. It involves introducing a tracer pulse at the feed of the cell and controlling the tracer concentration at its discharge. This technique provides the RTD function and the mean residence time $\left(t_{m}\right)$ and variance $\left(\sigma^{2}\right)$. This work presents and discusses the application of the RTD technique on mechanical flotation cells of the Rio Paracatu Mineração, Paracatu-MG. The results provided technical guidance towards which cells operate in better or worse mixing conditions.

Keywords: Flotation, hydrodynamics, residence-time distribution (RTD). 


\section{Introdução}

As células mecânicas de flotação são constituídas de um tanque. Nesse tanque atua um rotor (impelidor) envolvido por uma capa denominada estator. Como nas bombas centrífugas, o giro do rotor faz com que a polpa seja impelida na direção do topo do tanque, atingindo uma certa altura, a partir da qual a referida polpa experimenta movimento descendente, até atingir a região do rotor-estator, quando é novamente impelida na direção ascendente. Tal agitação intensa existe para promover, tanto a suspensão de partículas, como a dispersão das bolhas de ar no sistema (Schulze, 1984). A suspensão impede que os sólidos se sedimentem e causem aterramento da célula, além de maximizar a probabilidade de sua colisão com as bolhas. A dispersão de bolhas e partículas ao longo do volume da célula efetua a mistura das três fases (ar, sólidos e água). Quando tal mistura está sendo efetuada de maneira adequada, a ocorrência de zonas mortas ou curto-circuito é minimizada, oferecendo condições hidrodinâmicas mais apropriadas para um melhor desempenho do processo de flotação.

Se um engenheiro de processos minerais deseja caracterizar a qualidade da mistura das células mecânicas de flotação de seu circuito industrial ou piloto, ele poderá fazer uso de uma técnica muito utilizada no âmbito da indústria química ténica essa denominada de Distribuição de Tempos de Residência (DTR). A fundamentação dessa técnica assim como um estudo de caso de sua aplicação em circuito industrial constituem o objeto desse artigo.

Quando se dimensionam células mecânicas de flotação, faz-se uso do tempo de residência nominal $(\tau)$ da polpa no sistema, definido pela equação (1)

$$
\tau=\frac{V}{q_{o}}
$$

em que $V$ é o volume útil do tanque e $q_{o}$ é a vazão volumétrica de alimentação de polpa na entrada do sistema.
Devido ao fato de as células mecânicas serem tanques de mistura agitados, a polpa apresenta uma DTR cujo valor do tempo de residência médio $\left(t_{m}\right)$ pode diferir muito do tempo de residência nominal. De fato, esses valores são coincidentes apenas para o caso de um tanque operando perfeitamente. Nesse caso, tal situação pode propiciar a criação de um sistema fechado, ou seja, aquele no qual o fluido entra ou sai do equipamento com perfil de velocidades plano, não havendo, na entrada ou saída do sistema, ocorrência de difusão ou turbilhões (Levenspiel, 1974).

A determinação da curva de DTR é feita a partir de experimento realizado com traçador inerte, em que um pulso deste é injetado na corrente de alimentação do equipamento, quando, então, é medida a sua concentração (C) na corrente de saída como uma função do tempo (t). A Figura 1 ilustra como o experimento de DTR é realizado.

Obtidos os dados de concentração do traçador versus tempo, é feita a determinação da função DTR, que descreve quanto tempo as frações volumétricas da polpa permanecem dentro do tanque de flotação.

Analisando a curva de DTR, é possível a obtenção de informações pertinentes à hidrodinâmica do sistema real, através da comparação desta com a de tanques de mistura ideais. Dessa forma, podem ser detectadas a ocorrência de curto-circuito ou a presença de zonas de estagnação no equipamento.

As funções que caracterizam a DTR são, principalmente, a função $\mathrm{E}(\mathrm{t})$, chamada de função distribuição dos tempos de residência, o tempo de residência médio, $\left(t_{m}\right)$, e a variância, $\left(\sigma^{2}\right)$. Tais fun- ções são definidas pelas equações (2) a (4) (Fogler, 1970):

$$
\begin{aligned}
& E(t)=\frac{C(t)}{\int_{0}^{\infty} C(t) d t} \\
& t_{m}=\frac{\int_{0}^{\infty} t \cdot E(t) d t}{\int_{0}^{\infty} E(t) d t}=\int_{0}^{\infty} t \cdot E(t) d t \\
& \sigma^{2}=\int_{0}^{\infty}\left(t-t_{m}\right)^{2} E(t) d t
\end{aligned}
$$

Uma outra forma de expressar a DTR é através da função $\mathrm{F}(\mathrm{t})$, que é a função DTR cumulativa, definida pela equação (5).

$$
F(t)=\int_{0}^{t} E(t) d t
$$

A equação (5) que representa, diretamente, a fração de fluido que permanece dentro do tanque por um período menor ou igual a t.

Para representar os escoamentos reais são utilizados vários modelos matemáticos. Entre eles, o modelo dos tanques de mistura ideais em série constitui um método simples. Tal modelo utiliza os dados de DTR para diagnosticar o desempenho de tanques reais e possui apenas um parâmetro $(n)$, definido pela equação (6)

$n=\frac{\tau^{2}}{\sigma^{2}}$

A equação (6) estabelece o número de tanques de mistura ideais em série que representam o sistema real. Portanto, quanto maior o valor de $n$, melhor a qualidade da mistura apresentada pelas máquinas em operação. 
Odair Alves de Lima et al.

\section{Materiais e métodos}

Adotando-se o circuito industrial "scavenger" da Rio Paracatu Mineração - RPM, linhas A, B, C e D, em dezembro de 2004, foi aplicado um pulso do traçador $\mathrm{KCl}$, na entrada do primeiro tanque, e sua concentração foi medida na saída do último, em intervalos de tempo definidos. Os dados de concentração foram analisados por absorção atômica (emissão) e, aplicando a equação (2), foi determinada a função DTR da fase líquida em cada linha.

As condições operacionais e o número de tanques reais em série estão ilustrados na Tabela 1. As Tabelas 2 e 3 fornecem os parâmetros relevantes das células de flotação do circuito em questão.

Os dados de potência referem-se à potência fornecida ao eixo de rotação, considerando um rendimento líquido de 0,9 (Pirelli, 2001).

\section{Resultados}

A partir dos dados $\mathrm{E}(\mathrm{t})$ versus $\mathrm{t}$, ilustrados nas Figuras 2 a 5, onde podem ser observados o tempo de residência nominal $(\tau)$ e o tempo de residência médio $\left(t_{m}\right)$ e aplicando as equações de (3), (4) e (6), foram determinados o tempo de residência médio, a variância e o número de tanques ideais em série $(n)$, parâmetros necessários para caracterizar a DTR das células em operação e para representar o escoamento real do sistema. Esses resultados estão sumarizados na Tabela 4.

Nessa tabela, $\tau$ é o tempo de residência nominal; $t_{m}$ é o tempo de residência médio experimental; $\sigma^{2}$ é a variância; $\sigma$ é o desvio-padrão; e $n$ é o número de tanques ideais em série.

\section{Discussão}

As funções distribuição dos tempos de residência $E(t)$ para as quatro linhas do circuito "scavenger" da RPM são apresentadas nas Figuras 2 a 5. Em todas as situações, o formato da curva de DTR indica que cada sistema se comporta como um conjunto de tanques de
Tabela 1 - Condições operacionais do circuito "scavenger".

\begin{tabular}{c|c|c|c|c}
\hline Linha & $\begin{array}{c}\text { Vazão de } \\
\text { alimentação } \\
q_{0}\left(\mathbf{m}^{3} / \mathrm{min}\right)\end{array}$ & $\begin{array}{c}\text { Volume total } \\
\text { dos tanques } \\
\left(\mathbf{m}^{3}\right)\end{array}$ & $\begin{array}{c}\text { Teor de } \\
\text { sólidos } \\
(\mathbf{e m} \text { massa) } \\
(\%)\end{array}$ & $\begin{array}{c}\text { Número de } \\
\text { tanques reais } \\
\text { em série }\end{array}$ \\
\hline A & 24,3 & 489 & 34 & $14^{(*)}$ \\
\hline B & 21,4 & 489 & 28 & $14^{(*)}$ \\
\hline C & 23,2 & 508 & 36 & 4 \\
\hline D & 25,2 & 508 & 34 & 4 \\
\hline
\end{tabular}

${ }^{(*)}$ Distribuídos em duas linhas paralelas de 7 tanques.

Tabela 2 - Dados operacionais e aspectos geométricos das linhas A e B do circuito "scavenger".

\begin{tabular}{|c|c|c|c|c|c|c|c|}
\hline Linha & Fabricante & Células & $\begin{array}{c}\text { Rotação } \\
\text { do rotor } \\
\text { rpm }\end{array}$ & $\begin{array}{c}\text { Potência } \\
\text { kW }\end{array}$ & $H(m)$ & $\mathrm{T}(\mathrm{m})$ & $D(m)$ \\
\hline \multirow{14}{*}{ A } & \multirow{10}{*}{ Wemco } & 1 & 161 & 41,01 & \multirow{10}{*}{2,67} & \multirow{10}{*}{4,7} & \multirow{10}{*}{0,9} \\
\hline & & 2 & 165 & 44,67 & & & \\
\hline & & 3 & 165 & 36,42 & & & \\
\hline & & 4 & 165 & 38,98 & & & \\
\hline & & 5 & 168 & 36,66 & & & \\
\hline & & 6 & 165 & 44,47 & & & \\
\hline & & 7 & 165 & $\left({ }^{*}\right)$ & & & \\
\hline & & 8 & 165 & 45,23 & & & \\
\hline & & 9 & 165 & 38,18 & & & \\
\hline & & 10 & 166 & 49,83 & & & \\
\hline & \multirow{4}{*}{ Outokumpu } & 1 & 149 & 7,64 & \multirow{4}{*}{$\left({ }^{* \star}\right)$} & \multirow{4}{*}{3} & \multirow{4}{*}{0,7} \\
\hline & & 2 & 155 & 8,43 & & & \\
\hline & & 3 & 154 & 10,02 & & & \\
\hline & & 4 & 153 & 11,14 & & & \\
\hline \multirow{14}{*}{ B } & \multirow{10}{*}{ Wemco } & 1 & 165 & 41,05 & \multirow{10}{*}{2,67} & \multirow{10}{*}{4,7} & \multirow{10}{*}{0,9} \\
\hline & & 2 & 173 & 44,72 & & & \\
\hline & & 3 & 165 & 42,95 & & & \\
\hline & & 4 & 168 & 47,82 & & & \\
\hline & & 5 & 165 & 45,60 & & & \\
\hline & & 6 & 169 & 46,95 & & & \\
\hline & & 7 & 165 & 41,58 & & & \\
\hline & & 8 & 169 & 47,99 & & & \\
\hline & & 9 & 165 & 31,00 & & & \\
\hline & & 10 & 170 & 43,90 & & & \\
\hline & \multirow{4}{*}{ Outokumpu } & 1 & 153 & 12,19 & \multirow{4}{*}{$\left({ }^{* \star}\right)$} & \multirow{4}{*}{3} & \multirow{4}{*}{0,7} \\
\hline & & 2 & 160 & 10,85 & & & \\
\hline & & 3 & 147 & 10,79 & & & \\
\hline & & 4 & 155 & 8,90 & & & \\
\hline
\end{tabular}


mistura em série, conforme a literatura (Levenspiel, 1974). Aplicando-se as equações (3) a (6) aos dados coletados em cada linha, foram determinados o tempo de residência médio, a variância e o desvio-padrão de cada distribuição. Esses dados são apresentados na Tabela 4 , onde pode verificar-se que as linhas B, C e D operam com tempos de residência médios muito próximos, enquanto que a linha $\mathrm{A}$ apresenta o maior tempo (18 min).

Os desvios padrões apresentados pelas curvas de DTR (Tabela 4) sugerem que as linhas B, C e D apresentam uma baixa dispersão dos tempos de residência em torno do ponto médio, em comparação com a linha $A$, que apresenta um
Tabela 3 - Dados operacionais e aspectos geométricos das linhas C e D do circuito "scavenger".

\begin{tabular}{|c|c|c|c|c|c|c|c|}
\hline Linha & Fabricante & Células & $\begin{array}{c}\text { Rotação } \\
\text { do rotor } \\
\text { rpm }\end{array}$ & $\begin{array}{c}\text { Potência } \\
\text { kW }\end{array}$ & $H(m)$ & $\mathrm{T}(\mathrm{m})$ & D (m) \\
\hline \multirow{4}{*}{ C } & \multirow{4}{*}{$\begin{array}{l}\text { Wemco - } \\
\text { Smart Cell }\end{array}$} & 1 & 135 & 103,32 & \multirow{4}{*}{4,4} & \multirow{4}{*}{6,2} & \multirow{4}{*}{1,1} \\
\hline & & 2 & 144 & 97,77 & & & \\
\hline & & 3 & 135 & 114,08 & & & \\
\hline & & 4 & 135 & 116,48 & & & \\
\hline \multirow{4}{*}{ D } & \multirow{4}{*}{$\begin{array}{l}\text { Wemco - } \\
\text { Smart Cell }\end{array}$} & 1 & 125 & 99,7 & \multirow{4}{*}{4,4} & \multirow{4}{*}{6,2} & \multirow{4}{*}{1,1} \\
\hline & & 2 & 138 & 99,25 & & & \\
\hline & & 3 & 137 & 92,6 & & & \\
\hline & & 4 & 137 & 94,24 & & & \\
\hline
\end{tabular}

H - altura do tanque, T - diâmetro do equipamento, D - diâmetro do rotor.

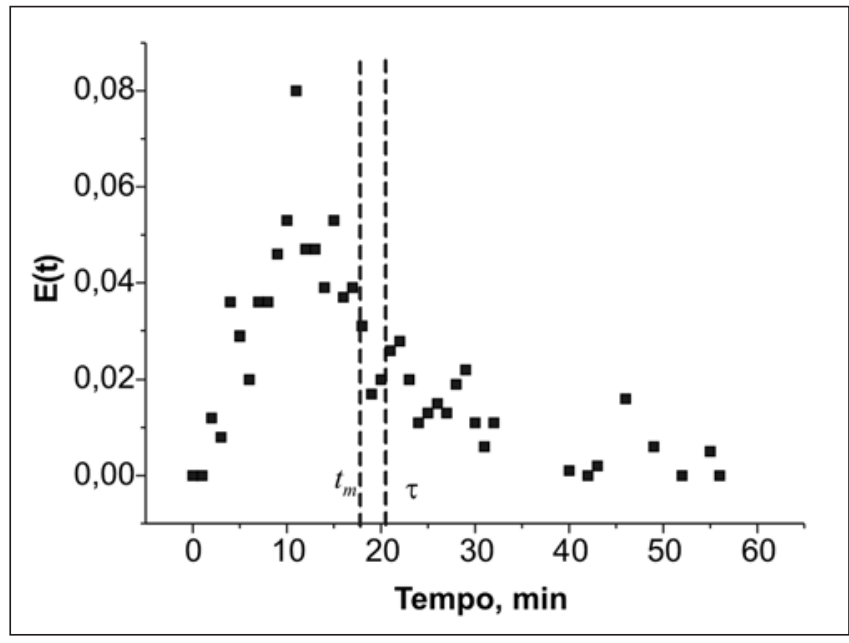

Figura 2 - DTR da linha A.

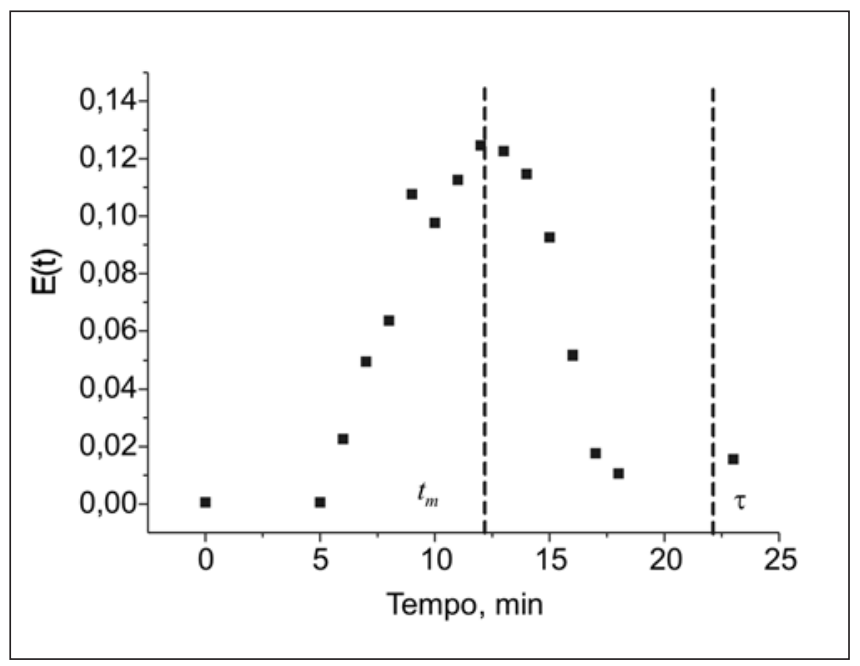

Figura 3 - DTR da linha B.

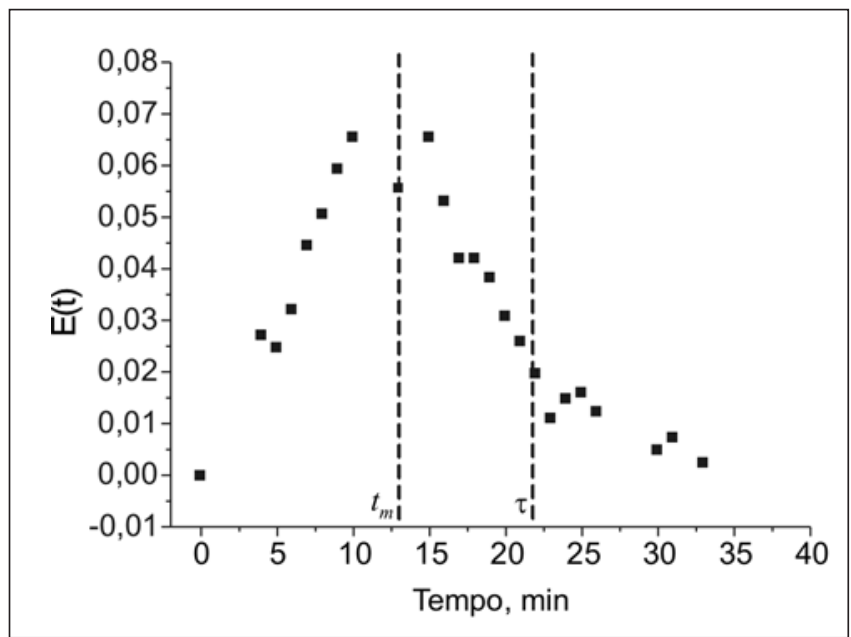

Figura 4 - DTR da linha C.

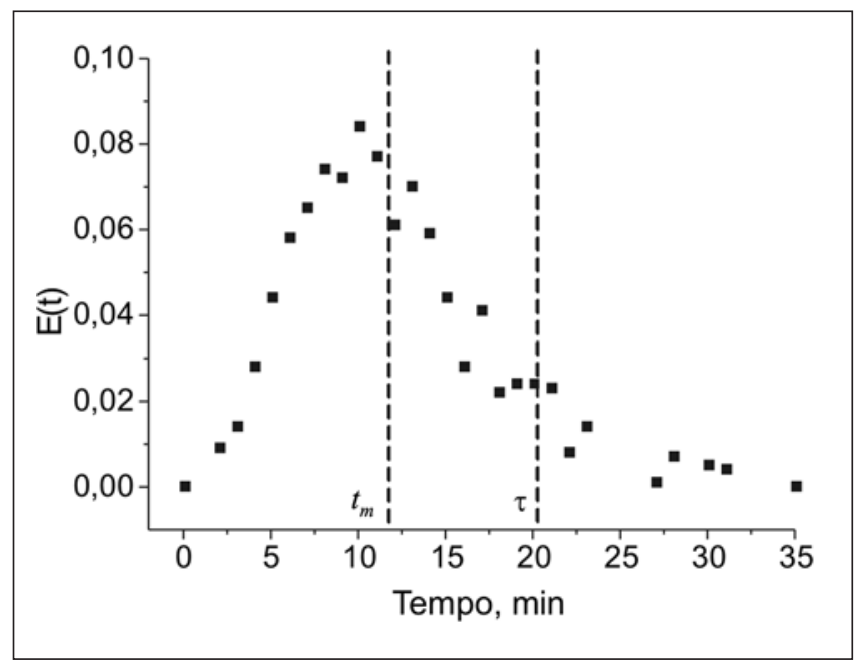

Figura 5 - DTR da linha D. 
Odair Alves de Lima et al.

valor bastante elevado, evidenciado pelo alto valor de sua variância. A Tabela 4 indica que as linhas B, C e D apresentam uma qualidade de mistura melhor do que a A, por possuírem um alto valor de $n$ (número de tanques de mistura ideais em série), quando comparado com o número de tanques reais em operação. Observa-se que, na linha A, o parâmetro $n$ é bem inferior ao número de células reais.

Os resultados do parâmetro $n$ mostram que as linhas B, C e D comportamse como 40, 12 e 12 tanques de mistura ideais, respectivamente; enquanto que os tanques em funcionamento na linha A desempenham a mesma função que apenas 3 tanques de mistura perfeita ideais em série. $\mathrm{O}$ baixo valor do parâmetro $n$ indica que as células estão operando numa condição hidrodinâmica inadequada, em que a polpa não apresenta uma boa mistura dentro do equipamento, comprometendo o resultado da operação. Para uma melhor visualização, foram construídas as curvas da função DTR cumulativa $F(t)$, como ilustrado na Figura 6.

A Figura 6 mostra que a polpa na linha Ademanda um tempo bem mais longo que a da linha B para sair do sistema, o que pode ser observado na Tabela 4, onde se percebe que a linha A apresenta uma vazão de alimentação maior que a B, $\mathrm{e}$, conseqüientemente, um tempo de residência nominal menor; no entanto, apresenta, na prática, um tempo de residência médio maior que a $\mathrm{B}$, de igual volume e de menor vazão de alimentação. Isto sugere que a mistura atuante nesse circuito não está adequada, provavelmente devido à presença de zonas de estagnação dentro do tanque.

Os resultados de DTR apresentados nesse trabalho foram obtidos através da determinação da concentração de um traçador químico $(\mathrm{KCl})$ susceptível à dissociação iônica na polpa de flotação. Desse modo, os resultados dizem respeito à distribuição dos tempos de residência da fase líquida. Para determinação da DTR da fase sólida, experimentos deveriam ser conduzidos utilizando materiais de mesma morfologia e granulometria do material processado, a fim de

Tabela 4 - Resultados de caracterização da DTR.

\begin{tabular}{c|c|c|c|c|c}
\hline Linha & $\tau(\min )$ & $t_{\boldsymbol{m}}(\min )$ & $\sigma^{2}\left(\min ^{2}\right)$ & $\sigma(\min )$ & $n(\tau / \sigma)^{2}$ \\
\hline A & 20 & 18 & 134,9 & 11,6 & 3 \\
\hline B & 23 & 13 & 13,0 & 3,6 & 40 \\
\hline C & 22 & 14 & 40,6 & 6,4 & 12 \\
\hline D & 20 & 12 & 34,0 & 5,8 & 12 \\
\hline
\end{tabular}

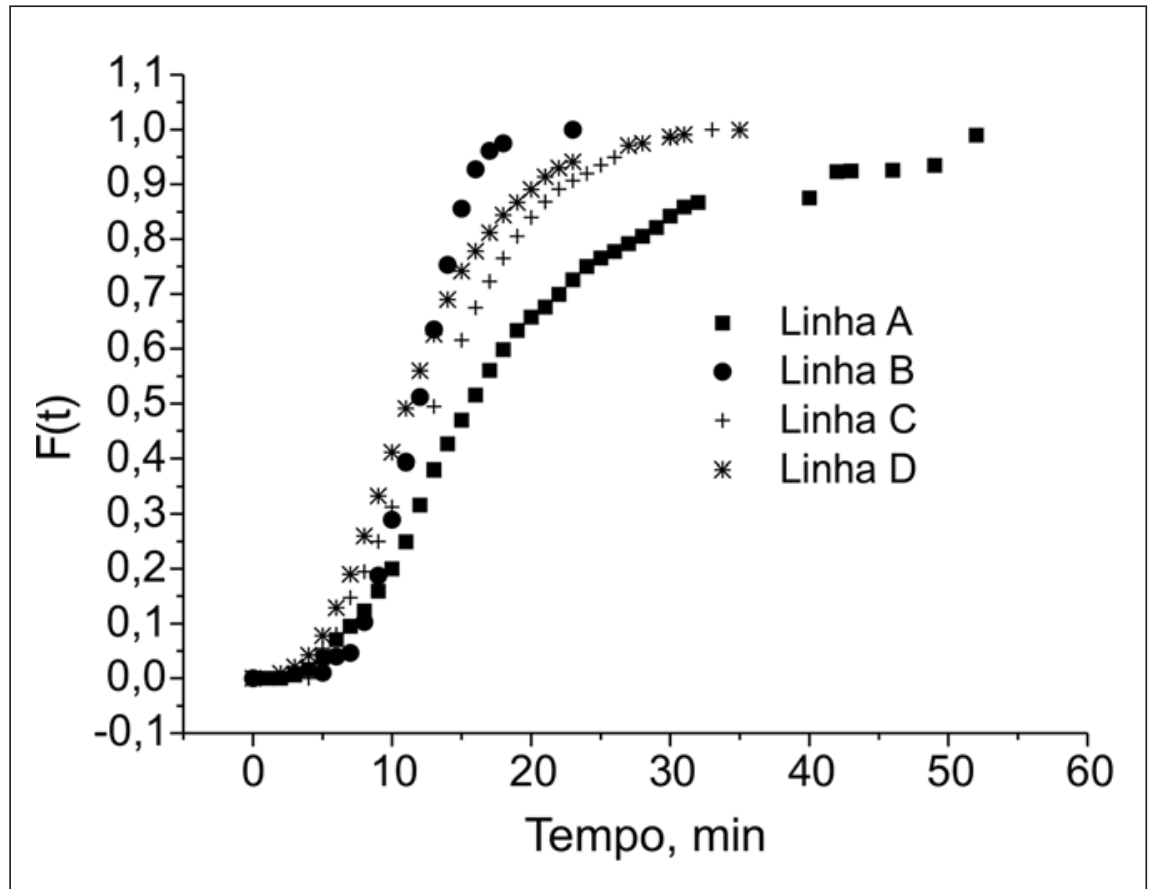

Figura 6 - Curvas de DTR cumulativas, $F(t)$.

se determinar o tempo de residência médio das partículas sólidas. No entanto, dados obtidos por Yianatos et al.(2001), para determinação da DTR das partículas sólidas em células industriais de flotação, mostraram que o tempo de residência médio dos sólidos é de 3 a $5 \%$ menor que o da fase líquida e, no caso das partículas finas, é da mesma ordem de grandeza.

\section{Conclusões}

O método de DTR constitui uma forma simples de análise da qualidade da mistura de células mecânicas de flotação, servindo, ainda, como uma poderosa ferramenta para diagnose do seu desempenho hidrodinâmico, indicando a presença de pontos de estagnação, ou a ocorrência de curto-circuito dentro do equipamento.

Essas informações são de suma importância para uma compreensão mais ampla da operação, permitindo diagnosticar o escoamento do sistema real de uma forma simples e possibilitando a implementação de medidas que visem à otimização do processo.

\section{Agradecimentos}

Os autores agradecem à RPM pelo suporte na execução do trabalho e permissão para publicação e à AMIRA (Australian Mineral Industry Research Association), pela oportunidade de participar do projeto P260D - Mineral Flotation. 


\section{Referências}

\section{bibliográficas}

FOGLER, H. S. Residence time distributions. In: __ Elements of chemical reaction engineering, Practice Hall, 1970 (International Series).

LEVENSPIEL, O. Engenharia das reações químicas. São Paulo: Editora Edgard
Blücher, Ed. da Universidade de São Paulo, 1974. v. 2.

PIRELLI. Manual Pirelli de Instalações Elétricas. 2. Ed. São Paulo: 2001.

SCHUlZE, H. J. Physico-chemical elementary processes in flotation - an analysis from the point of view of colloid science including process engineering considerations. Elsevier, 1984.
YIANATOS, J., BERGH, L., CONDORI, P. e AGUILERA, J. Hydrodynamic and metallurgical characterization of industrial flotation banks for control purposes Minerals Engineering. v. 14, n. 9, p. 10331046, 2001

Artigo recebido em 28/02/2005 e aprovado em 06/07/2005.

\title{
A Rem já está comemorando os seus 70 anos.
}

\section{Ela agora faz parte das}

\section{revistas indexadas pela Iniciativa dos Arquivos Abertos.}

\section{Added Archive}

\author{
Home Browse Analysis Register an \\ About Login Register Institutional Self-Archiving \\ Archive About Login Policy
}

The archive has been added to the suggestions list and will be reviewed by an admin.

Register another archive ...

URL of Home Page

Next

\begin{tabular}{|c|c|}
\hline url & http://www.rem.com.br/ \\
\hline name & REM - Revista Escola de Minas \\
\hline oai & http://www.rem.com.br/ojs/oai/ \\
\hline type & journal \\
\hline fulltext & 100 \\
\hline version & other \\
\hline status & live \\
\hline comment & $\begin{array}{l}\text { REM - Revista Escola de Minas é uma das mais antigas revistas técnicas da América do } \\
\text { Sul. Foi fundada em } 1936 \text { e desde então vem se especializando em publicar artigos na } \\
\text { área de Engenharia. Seu objetivo é de servir como meio de divulgação aos trabalhos } \\
\text { técnico-científicos dos pesquisadores nacionais e estrangeiros naquela área. Circula em } \\
\text { empresas do setor mínero-metalúrgico, nos órgãos governamentais do ramo, centros } \\
\text { pesquisas nacionais e estrangeiros e em universidades e escolas do Brasil e do exterior. }\end{array}$ \\
\hline country & $\mathrm{br}$ \\
\hline adminemail & editor@rem.com.br \\
\hline \multicolumn{2}{|c|}{ recordcount } \\
\hline datestamp & 20050725 \\
\hline ip & 201.19 .89 .95 \\
\hline
\end{tabular}

Copyright 2005 Tim Brody <tdb01r@ecs.soton.ac.uk>, University of Southampton.

@) This work is licenced under a Creative Commons Licence.

